\title{
Modeling and Simulation of a Multi-agent Green Supply Chain Management System for Retailers
}

\author{
Danfeng Wei \\ School of Vocational \& Technical Education, Harbin University of Commerce, Harbin 150028, China
}

Corresponding Author Email: Wdfgwj@126.com

https://doi.org/10.18280/jesa.530414

Received: 8 May 2020

Accepted: 3 August 2020

\section{Keywords:}

retailer, multi-agent, green supply chain (GSC), game model

\begin{abstract}
In recent years, the agent technology has been successfully applied in supply chains, thanks to its excellent interactivity, proactivity, and autonomy. However, the existing research on multi-agent green supply chain (GSC) stops on the strategic and tactical levels, failing to implement the relevant supply chain models. To overcome the limitation, this paper designs a multi-agent GSC management system for retailers, with the aim to obtain scientific collaboration strategies among multiple agents and to make effective logistics decisions for the supply chain. Firstly, a 3-layer hierarchical evaluation index system (EIS) was established under the framework of the multi-agent GSC management system. Next, the authors modeled the supply-demand relationship and dynamic game of multi-agent GSC, and discussed the cooperation and negotiation models among multiple agents. Experimental results show that the proposed multi-agent GSC management model is highly effective. The research findings provide a reference for the application of multiagent technology in other types of supply chain enterprises.
\end{abstract}

\section{INTRODUCTION}

Based on supply chain management and green manufacturing, green supply chain (GSC) fully considers factors like resource efficiency and environmental impact in supply chain management, aiming to minimize the negative impact on environment, maximize the utilization of resources, and optimize the coordination between economic and social benefits of the supply chain, across the entire lifespan of products (e.g. material acquisition, design, production, packaging, transport, storage, sales, use, scrapping, and recycling) [1-4].

With the rapid development of artificial intelligence (AI), the agent technology has been widely used in distributed systems, thanks to its excellent interactivity, proactivity, and autonomy. Significant research progress has been achieved in the supply chain application of agent technology. Fully integrating multiple subjects (e.g. resource, equipment, manpower, and capital), the agent technology makes enterprise supply chain system more flexible and agile [5-8].

Currently, there is a growing interest in the multi-agent modeling of GSC system. Many scholars have simulated the operation of actual GSCs, in an attempt to reorganize and support the decision-making in GSC operation. The existing studies on GSC mainly adopt quantitative methods like questionnaire survey and case analysis [9-11]. Based on decision support modeling, Fahimnia et al. [12] examined a two-echelon supply chain composed of producers and retailers, and discussed the beneficial effects of green products on the decentralized decision-making during price negotiation. Mishra et al. [13] studied how green product design is affected by product type, supply chain structure and competition type in in a competitive environment, and constructed a reasonable evaluation index system (EIS) for supply chain greenness.
Sarkis and Dou [14] built a three-stage GSC game model, and attributed the growing profit of supply chain members to their dominance in the game. From the perspective of consumers, Uygun and Dede [4] coordinated the benefit distribution of GSC members according to their sensitivity to green products and the income sharing contract.

In recent years, the Chinese government has provided a series of financial subsidies to the enterprises that take measures to protect the environment and the consumers who purchase green products. For example, the National Development and Reform Commission (NDRC), in association with the Ministry of Industry and Information Technology and the Ministry of Finance, has launched the Energy-Efficient Products for the Benefit of the People Program. Against this backdrop, some scholars have explored the diffusion of GSC management between enterprises during the distribution of government subsidy [4, 15]. Coskun et al. [16] combined different tax systems and incentive subsidy policies, and analyzed their impacts on GSC and green manufacturing. $\mathrm{Yu}$ et al. [17] constructed three green manufacturing decision-making models under uncertain demand, namely, the reward and penalty mechanism model, the non-government intervention model, and the tax-subsidy mechanism model, and discovered that the reward and penalty mechanism is the best model to incentivize supply chain members to recycle and remanufacture waste products. Ameknassi et al. [6] suggested that the performance of the reverse supply chain can be effectively improved by elevating the price of product recovery and government subsidy, and established a model to optimize the government subsidy and product recovery price for reverse supply chain.

In supply chain management, the multi-agent technology is mainly applied in two aspects: model establishment and system realization [18-20]. Alananzeh et al. [21] proposed a 
collaborative mechanism for multi-agent social organizations in a distributed environment, and introduced the mechanism to the supply chain. Younis and Sundarakani [22] created a multi-agent collaboration framework for the production and sales of the supply chain, explained the basic operation flow of the framework, and provided a satisfactory production-sales collaborative plan for the supply chain, providing an effective solution to the information heterogeneity across platforms and languages.

To sum up, the existing research on multi-agent GSC stops on the strategic and tactical levels, failing to implement the relevant supply chain models. To overcome the limitation, this paper designs a multi-agent GSC management system for retailers, with the aim to obtain scientific collaboration strategies among multiple agents and to make effective logistics decisions for the supply chain.

The remainder of this paper is organized as follows: Section 2 provides the framework of the multi-agent GSC management system, and sets up a 3-layer hierarchical EIS for system greenness; Section 3 models the supply-demand relationship and dynamic game of multi-agent GSC; Section 4 designs the multi-agent GSC management model for retailers, and discusses the cooperation and negotiation models among multiple agents; Section 5 verifies the effectiveness of the proposed multi-agent GSC management model; Section 6 puts forward the conclusions.

\section{SYSTEM MODEL AND EIS}

To improve GSC management and better coordinate GSC members, this paper firstly designs the framework of the multi-agent GSC management system. The GSC needs to fully consider environmental impact and resource optimization throughout the lifespan of products, trying to minimize the negative environmental impact and optimize the coordination between social and economic benefits. In the multi-agent GSC management system, the subjects should be able to solve problems independently, and maintain flexible, close communication and good collaboration with each other. If the collaboration is poor, the correlation between the three common flows between them, namely material flow, information flow, and capital flow, will be weakened, and the GSC will become highly uncertain. In this case, the total green cost of the supply chain will soar.

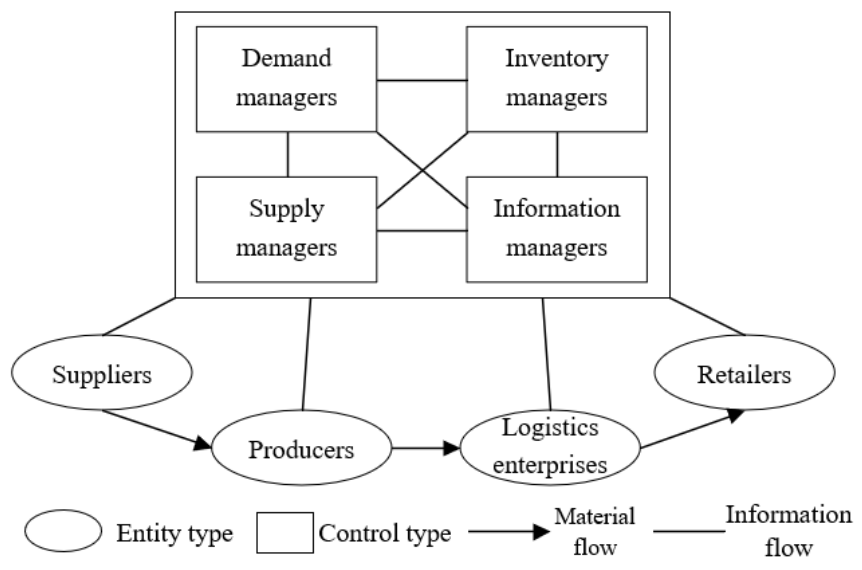

Figure 1. The framework of the multi-agent GSC management system
Figure 1 shows the framework of the multi-agent GSC management system. The subjects in the system fall into two categories: entity type and control type. The entity type subjects mainly include the suppliers of provides raw materials or parts, the producers that produce and assemble products, and the retailers who sell the obtained products.

The control type subjects mainly include the demand managers that estimate delivery dates based on product type and inventory, the inventory managers that that handle inventory-related tasks, supply managers that select suppliers and prepare procurement contracts, and information managers that provide periodic information (e.g. corporate strategies) and produce real-time information.

To measure the greenness of the proposed system, a 3-layer hierarchical EIS was designed. There are six primary indices in the EIS: green material, green design, green manufacturing, green logistics, green management, and green product.

(1) The green material was characterized by the utilization, recycling rate, and harmfulness of materials;

(2) The green design was characterized by the cost, equipment quality, and staff ratio of green design;

(3) The green manufacturing was characterized by the process and technical level, the cleanness of work environment, the control level of the three wastes (solid waste, wastewater, and waste gas), and the greenness of energy consumption;

(4) The green logistics was characterized by the greenness of transport, green packaging, green warehousing, and recycling and reuse rate;

(5) The green management was characterized by the environmental management level of supply chain partners, the proportion of environmental management personnel in the total staff, social recognition, and employee green awareness;

(6) The green product was characterized by environmental friendliness, waste product recovery rate, and economy.

\section{SUPPLY-DEMAND MODEL AND DYNAMIC GAME MODEL}

Previous studies mainly tackled the game between the government and one or two enterprises, rather than the game between the government and multiple enterprises. This paper takes multiple factors into consideration to model the supplydemand relationship and dynamic game of the GSC: the greenness of the supply chain, the price of green products, the demand and environmental preference of each consumer, total consumer demand, and the amount of government subsidy.

\subsection{Supply-demand model}

Figure 2 illustrates the structure of GSC supply-demand model. Based on his/her green demand, each consumer weigh and make purchases. The enterprises produce green products, implement green operation, perform green management, adopt green logistics, and sell green products, in the light of consumer demand. The government conduct macro-control through subsidy and penalty, under the premise of maximizing the interests of consumers and enterprises and the optimal coordination of economic benefit, social benefit, and environmental impact of green products. From the angle of consumer demand chain and enterprise supply chain, this paper looks for the optimal government subsidy to balance the supply and demand in the market. 


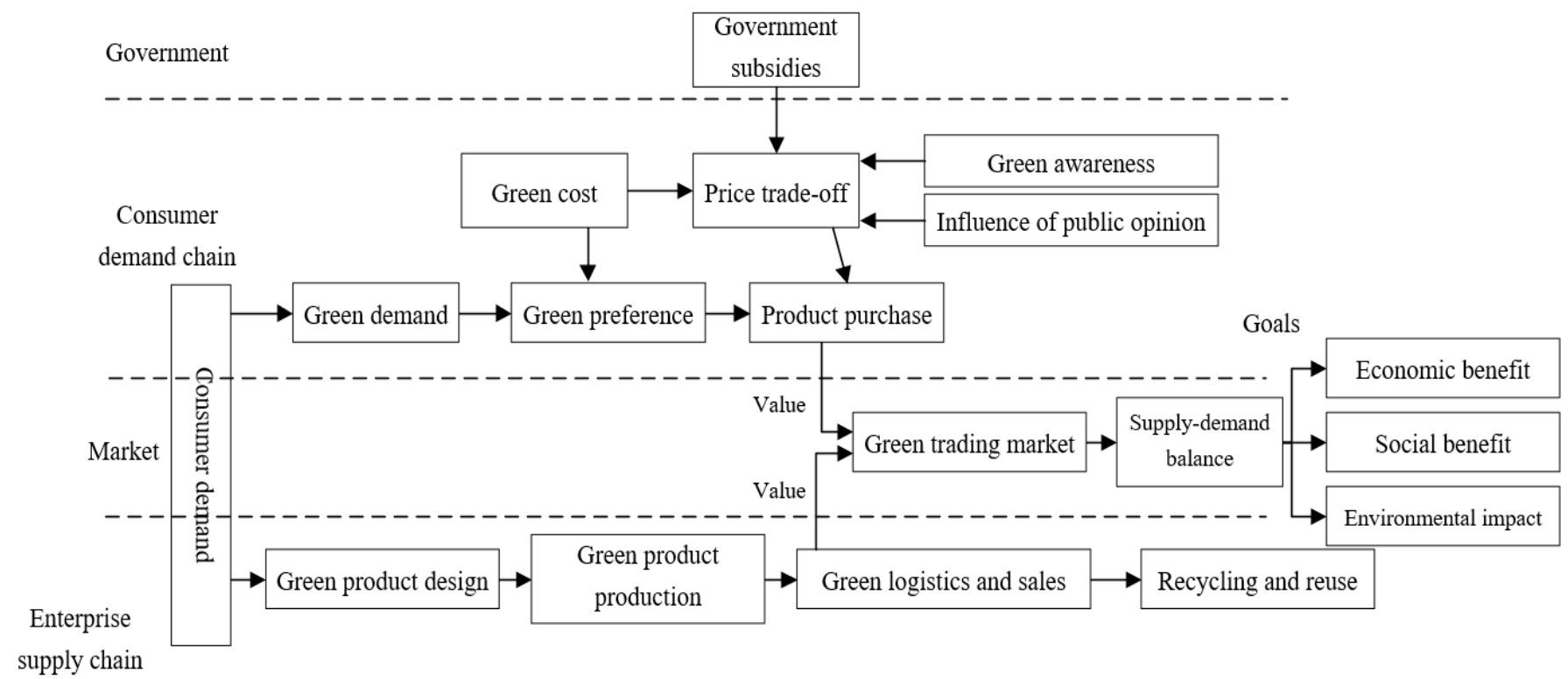

Figure 2. The structure of GSC supply-demand model

(1) Analysis on consumer demand chain

Let $g_{1}$ and $p_{1}$ be the greenness and price of type I green products falling short of the requirements of government subsidy, respectively; $g_{2}$ and $p_{2}$ be the greenness and price of type II green products surpassing the requirements of government subsidy, respectively. The greenness and prices of the two types of products satisfy $g_{2}>g_{1}>0$ and $p_{2}>p_{1}$. Assuming that the consumer preference $\rho$ for green products is evenly distributed in $[0,1]$, then the relationship between consumer surplus $R$ and $\rho$ can be expressed as:

$$
\left\{\begin{array}{l}
R_{1}=\rho g_{1}-p_{1} \\
R_{2}=\rho g_{2}-p_{2}
\end{array}\right.
$$

The consumer preferences for type I and type II green products can be calculated by $\rho_{1}=p_{1} / g_{1}$, and $\rho_{2}=p_{2} / g_{2}$, respectively. Let $N$ be the total number of consumers. Then, the consumer demands for type I and type II green products can be respectively computed by:

$$
\left\{\begin{array}{l}
d_{1}=\left(\rho_{2}-\rho_{1}\right) N=\left(\frac{p_{2}}{g_{2}}-\frac{p_{1}}{g_{1}}\right) N \\
d_{2}=\left(1-\rho_{2}\right) M=\left(1-\frac{p_{2}}{g_{2}}\right) N
\end{array}\right.
$$

(2) Analysis on enterprise supply chain

Type II green products, which surpass the requirements of government subsidy, require better scientific investment, production process, and product technology. Therefore, the marginal production cost of type II green products must be higher than that of type I products: $a_{2}>a_{1}$. Let $s$ be the government subsidy for type I green products. Then, the enterprise profits of producing types I and II green products can be respectively calculated by:

$$
\left\{\begin{array}{c}
\mu_{1}=\left(p_{1}-a_{1}\right) d_{1}=\left(p_{1}-a_{1}\right)\left(\frac{p_{2}}{g_{2}}-\frac{p_{1}}{g_{1}}\right) N \\
\mu_{2}=\left(p_{2}-a_{2}+s\right) d_{2}=\left(p_{2}-a_{2}+s\right)\left(1-\frac{p_{2}}{g_{2}}\right) N
\end{array}\right.
$$

The enterprise profits can be maximized under the following condition:

$$
\frac{\partial \mu_{1}}{\partial p_{1}}=0, \frac{\partial \mu_{2}}{\partial p_{2}}=0
$$

Then, the optimal prices for types I and II green products can be respectively obtained by:

$$
\left\{\begin{array}{c}
\hat{p}_{1}=\frac{g_{2} g_{1}+2 g_{2} a_{1}+g_{2} a_{2}-g_{1} s}{4 g_{2}} \\
\hat{p}_{2}=\frac{g_{2}+a_{2}-s}{2}
\end{array}\right.
$$

Substituting the results of (5) into (2), the optimal supplies of types I and II green products can be respectively obtained as:

$$
\left\{\begin{array}{c}
\hat{d}_{1}=\frac{\left(g_{1} a_{2}+g_{1} s+g_{2} g_{2}-2 g_{2} a_{1}\right)}{4 g_{1} g_{2}} N \\
\hat{d}_{2}=\frac{\left(g_{2}+s-a_{2}\right)}{2 g_{2}} N
\end{array}\right.
$$

Substituting (6) into (3), the optimal enterprise profits can be obtained as:

$$
\left\{\begin{array}{c}
\hat{\mu}_{1}=\frac{\left(g_{1} a_{2}+g_{1} s+g_{1} g_{2}-2 g_{2} a_{1}\right)^{2}}{16 g_{1} g_{2}^{2}} N \\
\hat{\mu}_{2}=\frac{\left(g_{2}+s-a_{2}\right)^{2}}{4 g_{2}} N
\end{array}\right.
$$

Comparing the signs of the partial derivatives of $s$ in (5)-(7):

$$
\begin{aligned}
& \frac{\partial \hat{p}_{1}}{\partial s}<0, \frac{\partial \hat{p}_{2}}{\partial s}<0, \frac{\partial \hat{d}_{1}}{\partial s}<0 \\
& \frac{\partial \hat{d}_{2}}{\partial s}>0, \frac{\partial \hat{\mu}_{1}}{\partial s}<0, \frac{\partial \hat{\mu}_{2}}{\partial s}>0
\end{aligned}
$$

Formula (8) shows that, after the government offer subsidy, the prices of types I and II green products both decline; the demand and profit of type I green products drop, while those of type II green products rise. 
(3) Optimal subsidy method

The government usually resorts to new economic policies to subsidize the enterprises producing type II green products, and to encourage and guide green enterprises in the supply chain. In this process, the supply and demand in the GSC can be balanced by optimizing the subsidy policy with the goal of maximizing social welfare. The total consumer surplus $R_{\text {total }}$ can be expressed as:

$$
R_{\text {total }}=\left[\int \begin{array}{c}
\rho_{2} \\
\rho_{1}
\end{array}\left(\rho g_{1}-p_{1}\right) d \rho+\int \quad \rho_{1}\left(\rho g_{2}\right.\right.
$$

The producer surplus $P$ can be defined as:

$$
P=\hat{\mu}_{1}+\hat{\mu}_{2}
$$

Then, the social welfare $S W$ can be calculated by:

$$
S W=U_{\text {total }}+P+v d_{2}-\tau d_{1}-s d_{2}
$$

where, $v$ is the environmental cost of purchasing type I green products; $\tau$ is the environmental benefit of purchasing type II green products. To maximize social benefit, i.e. make $\mathrm{d} S W / \mathrm{d} s=0$, the optimal amount of government subsidy can be calculated by:

$$
\hat{s}=\frac{\begin{array}{r}
6 g_{2} a_{1}+4 v g_{2}+8 \tau g_{2}-3 g_{1} a_{2} \\
-3 g_{1} g_{2}-4 g_{2} a_{2}-12 g_{2}^{2}
\end{array}}{4 g_{2}-3 g_{1}}
$$

\subsection{Dynamic game model}

The GSC supply-demand model was optimized to build a three-stage dynamic game model between the government and multiple agents (enterprises). The three stages of the game include determining the objective of decision-making on subsidy and the amount of subsidy for green products; determining whether to implement GSC management; setting the price for the green products among enterprises choosing different green strategies. The relevant parameters of the model are defined as follows:

$D_{p o t}$ is the potential market capacity; $p_{G}$ and $c_{G}$ are the price and cost of green products meeting the requirements of government subsidy, respectively; $p$ and $c$ are the price and cost of green products, respectively; $d_{b}$ and $d_{a}$ are the product demands before and after GSC management, respectively; $\mu_{S-}$ ${ }_{b}$ and $\mu_{S-a}$ are the profits of an agent (enterprise) before and after GSC management, respectively; $\mu_{G-b}$ and $\mu_{G-a}$ are the profits of multiple agents (enterprises) before and after GSC management, respectively; $\sigma$ is the consumer evaluation of the products before GSC management. Then, the market demands for the products before and after GSC management can be respectively expressed as:

$$
\begin{gathered}
d_{b}=D_{p o t} \int_{p_{G}}^{\frac{p-p_{G}}{\rho-1}} 1 d u(\sigma)=\frac{p-p_{G}}{\rho-1}-p_{G}=\frac{p-\rho p_{G}}{\rho-1} \\
d_{a}=D_{p o t} \int_{\frac{p-p_{G}}{\rho-1}}^{D_{p o t}} 1 d u(\sigma)=D_{p o t}-\frac{p-p_{G}}{\rho-1}
\end{gathered}
$$

where, $u(\sigma)=\sigma / D_{p o t}$ is the cumulative distribution function of $\sigma$, which reflecting consumer's willingness to pay. Then, the sum of consumer surpluses after purchasing the products before and after GSC management can be respectively calculated by:

$$
\begin{gathered}
R_{b}=\left(\int_{p_{G}}^{\frac{p-p_{G}}{\rho-1}} \frac{\sigma}{\frac{p-p_{G}}{\rho-1}-p_{G}} d \sigma-p_{G}\right) d_{b} \\
=\frac{d_{b}\left(p-\rho p_{G}\right)}{2(\rho-1)} \\
R_{a}=\left(\int_{\frac{p-p_{G}}{\rho-1}}^{D_{p o t}} \frac{\rho \sigma}{D_{p o t}-\frac{p-p_{G}}{\rho-1}} d \sigma-p\right) d_{a} \\
=\frac{d_{a}\left(\rho(\rho-1) D_{p o t}+2 p-\rho p-\rho p_{G}\right)}{2(\rho-1)}
\end{gathered}
$$

Thus, the expected profit of enterprise before GSC management can be described as:

$$
E_{b}=\mu_{b}=\left(p_{G}-c_{G}\right) \frac{p-\rho p_{G}}{D_{p o t}(1-\delta)(\rho-1)}
$$

where, $Q$ is the number of multiple agents (enterprises); $\delta$ is the proportion of enterprises implementing GSC management. Then, the expected profit of enterprise after GSC management can be described as:

$$
\begin{aligned}
E_{a}=\mu_{a}=[p- & (1 \\
& \left.+g) c_{G}\right] \frac{D_{p o t}(\rho-1)-\left(p-p_{G}\right)}{\delta Q(\rho-1)}
\end{aligned}
$$

Then, the total expected profit of enterprise can be expressed as:

$$
E=\delta E_{a}+(1-\delta) E_{b}
$$

Whereas the enterprises differ in the dynamic change speed of GSC management, the dynamic change ratio of enterprises implementing GSC management can be depicted as:

$$
\begin{aligned}
\frac{d \delta}{d t}=\delta(1-\delta)[ & (p-(1 \\
& \left.+g) c_{G}\right) \frac{D_{p o t}(\rho-1)-\left(p-p_{G}\right)}{\delta Q(\rho-1)} \\
& \left.-\left(p-c_{G}\right) \frac{p-\rho p_{G}}{Q(1-\delta)(\rho-1)}\right]
\end{aligned}
$$

Let the value of (20) be zero. Then, the steady state can be expressed as:

$$
\begin{gathered}
\tilde{\delta}=\frac{\left[p-(1+g) c_{G}\right]}{\left[D_{p o t}(\rho-1)-\left(p-p_{G}\right)\right]} \\
+\left[p-(1+g) c_{G}\right]\left[D_{p o t}(\rho-1)-\left(p-p_{G}\right)\right] \\
\frac{d u(\delta)}{d \delta}=-\left(p_{G}-c_{G}\right) \frac{p-\rho p_{G}}{Q(\rho-1)} \\
-\left[p-(1+g) c_{G}\right] \frac{D_{p o t}(\rho-1)-\left(p-p_{G}\right)}{Q(\rho-1)}
\end{gathered}
$$

As shown in (22), when the output and profit of the enterprise are both greater than zero, the steady state value of the dynamic change ratio falls in $[0,1]$, and its cumulative distribution function is a decreasing function, whose value is 
always below zero. In other words, the dynamic change ratio of our dynamic game model is stable, if the dynamic change ratio is greater than the steady state value and the cumulative distribution function is below zero, or if the dynamic change ratio is smaller than the steady state value and the cumulative distribution function is above zero.

Similarly, after consumers receive government subsidy, the speed of the dynamic change ratio of the enterprises implement GSC management can be expressed as:

$$
\begin{gathered}
u^{S}(\delta)=\delta^{S}\left(1-\delta^{S}\right)\left[p^{S}-(1+g) c_{G}\right] \\
\frac{D_{p o t}(\rho-1)-\left(p^{S}-\delta s-p_{G}^{S}\right)}{x^{S} Q(\rho-1)} \\
-\left(p_{G}^{S}-c_{G}\right) \frac{p^{S}-\delta s-\eta p_{G}^{S}}{Q\left(1-\delta^{S}\right)(\rho-1)} \\
\tilde{\delta}^{S}=\frac{\left[p^{S}-(1+g) c_{G}\right]}{\left[D_{p o t}(\rho-1)-\left(p^{S}-g s-p_{G}^{S}\right)\right]} \\
+\left[p_{G}^{S}-(1+g) c_{G}\right]\left[D_{p o t}(\rho-1)-\left(p^{S}-g s-p_{G}^{S}\right)\right]
\end{gathered}
$$

The derivative of $u^{S}\left(\delta^{S}\right)$ with respect to $\delta^{S}$ can be obtained as:

$$
\begin{gathered}
\frac{d u^{S}\left(\delta^{S}\right)}{d \delta^{S}}=-\left(p_{G}^{S}-c_{G}\right) \frac{p^{S}-g S-\rho p_{G}^{S}}{Q(\rho-1)} \\
-\left[p^{S}-(1+g) c_{G}\right] \frac{D_{p o t}(\rho-1)-\left(p^{S}-g s-p_{G}^{S}\right)}{Q(\rho-1)}
\end{gathered}
$$

It can be seen that, if an enterprise has received government subsidy, the dynamic change ratio of the dynamic game model is stable, if its profit and output are both greater than zero.

\section{MULTI-AGENT GSC MANAGEMENT MODEL FOR RETAILERS}

Based on the GSC supply-demand model and dynamic game model, the subjects of the multi-agent GSC management model for retailers are divided into five categories by functions: demand managers, inventory managers, cost managers, communication managers, and return managers.

(1) The demand manager handles the demand of consumers, and owns a green subject database, which contains the inventory information on the green products of all retailers.

(2) The inventory manager continuously updates the green inventory of retailers, manages and stores inventory information, and updates the orders and return requests from other subjects in real time.

(3) The cost manager counts all the costs of retailers, and provides data and information supports to GSC cost statistics.

(4) The communication manager exchanges information with producers and consumers.

(5) The return manager classifies the reasons for return and the returned green products, receives, stores, or sends the returned products, and instructs the inventory manager to update the green product inventory. The return manager owns a database containing the return information of all retailers.

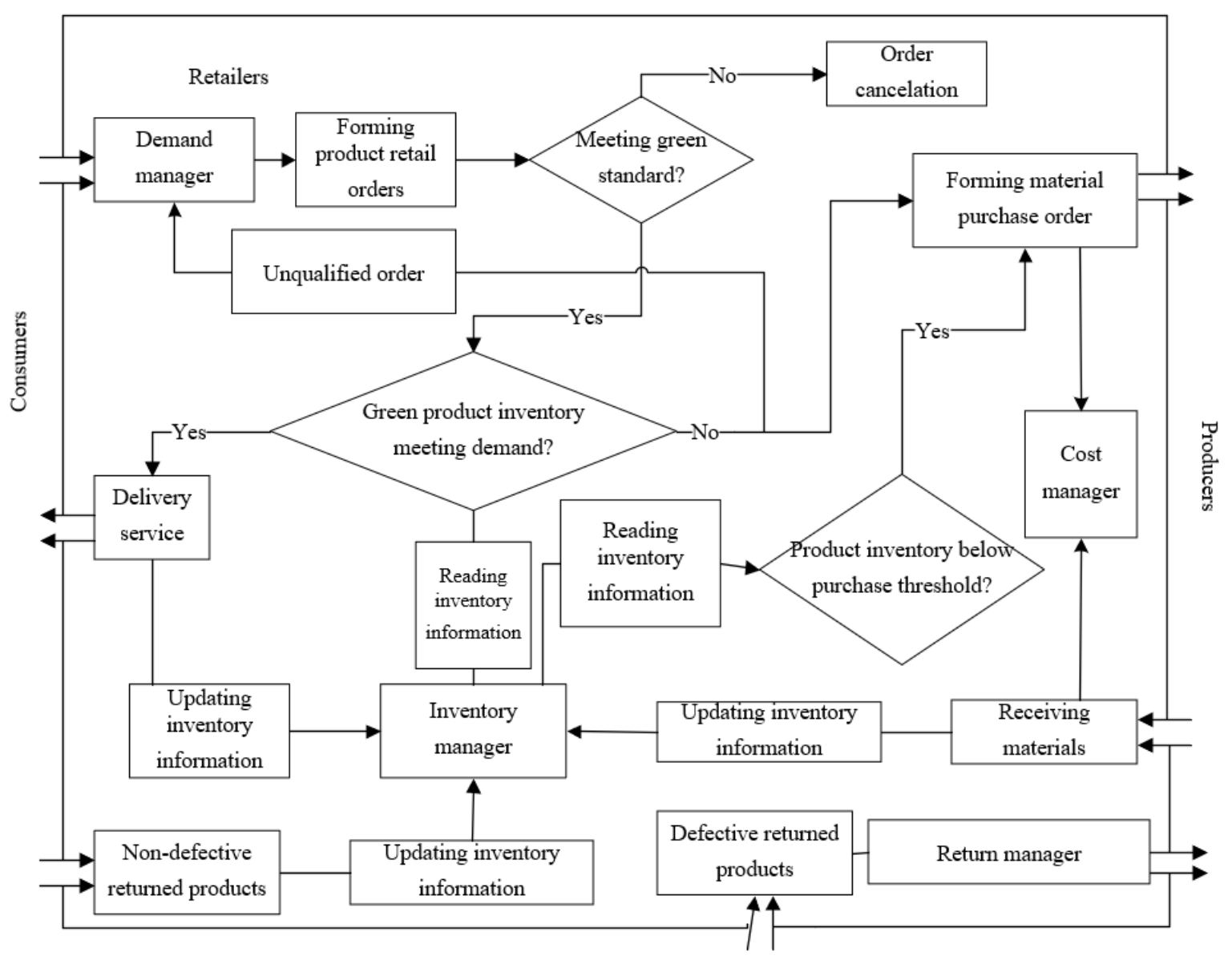

Figure 3. The structure of the multi-agent GSC management model for retailers 


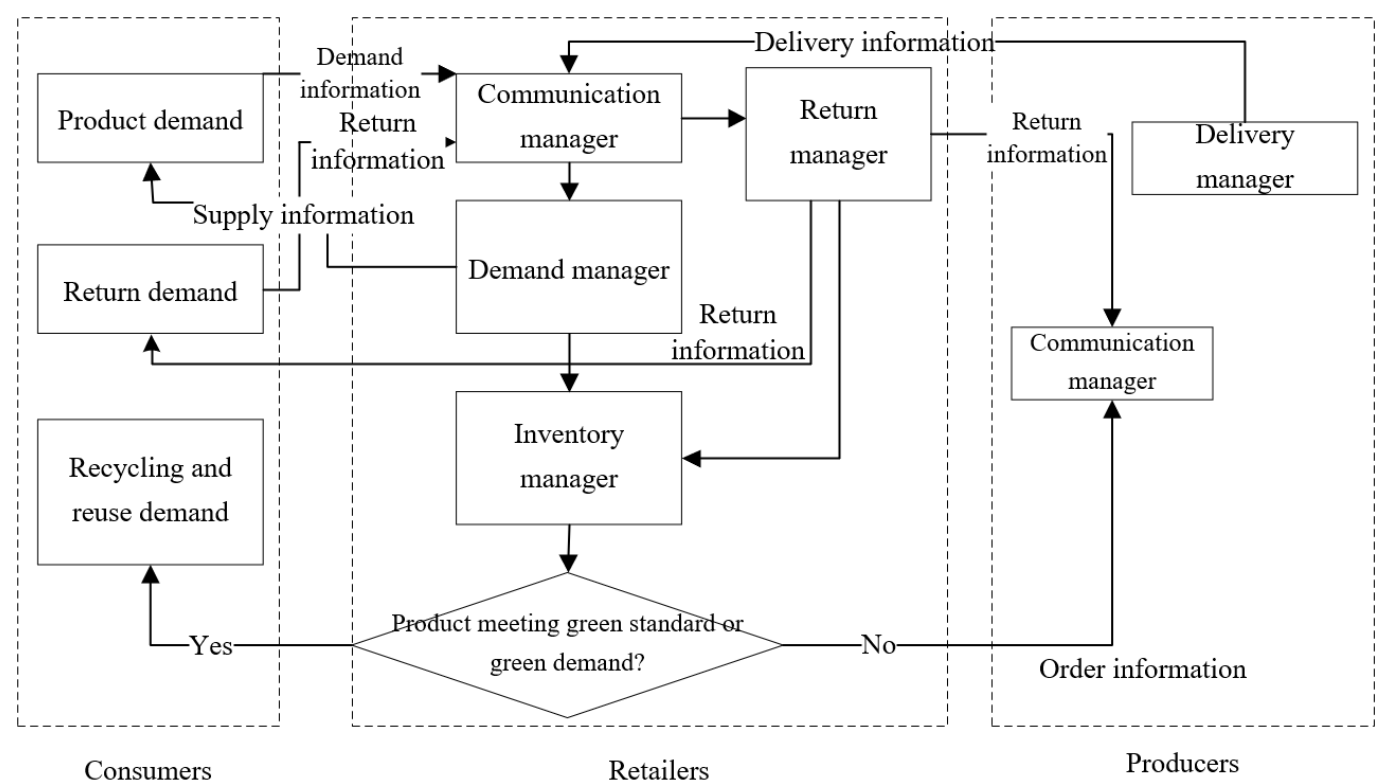

Figure 4. The internal operation flows of the multi-agent GSC management model for retailers

Figure 3 shows the structure of the multi-agent GSC management model for retailers. Apart from the enterprise operators, our model reflects the links directly related to consumers, such as demand management and return management.

The internal operation flows of the multi-agent GSC management model for retailers is described in Figure 4 as:

(1) Product demand process: After being informed by the communication manager about the consumer demand, the demand manager interacts with the inventory manager, and chooses to supply the product to consumers or to purchase the product from the producer.

(2) Product return process: After being informed by the communication manager about the return, the return manager classifies the reason for the return and the returned product, receives the returned green product, chooses to store or to return the green product to the producer, and updates the inventory information.

(3) Product supply process: After being informed by the communication manager about the green product supply information of the producer, the inventory manager receives the supplied product, and updates the inventory information.

(4) Cost management process: The cost manager counts and updates the total GSC operating cost in real-time.

The multi-agent GSC management environment for retailers is open and dynamic. The multiple subjects in the environment have different goals. To realize scientific management of their goals and resources, it is necessary to optimize the cooperation and negotiation models between them. Suppose A and B are two independent subjects in the multi-agent GSC management system for retailers. The set of their green preference states can be established as:

$$
S_{\text {gre }}=\left\{s_{1}, s_{2}, \ldots, s_{n}\right\}
$$

The utility functions of A and B can be respectively defined as:

$$
\left\{\begin{array}{l}
y_{A}=S_{g r e} \rightarrow r_{A} \\
y_{B}=S_{g r e} \rightarrow r_{B}
\end{array}\right.
$$

where, $r_{\mathrm{A}}$ and $r_{\mathrm{B}}$ are the real numbers assigned to the utility functions of the two subjects. The greater the numbers, the more favorable the current state is for A and B. Let $s$ and $s^{*}$ be the green preference states in the set $S_{\text {gre }}$. The cooperative game between the subjects can be modeled as:

$$
y_{A}(s)=y_{B}\left(s^{*}\right)
$$

That is, the state of subject A is favorable at least under conditions $s$ and $s^{*}$ :

$$
s \geq s^{*}
$$

If one subject prefers the green preference state $s^{*}$ over $s$, while the other subject prefers $s$ over $s^{*}$, the two parties of the game have opposite green preferences. This calls for negotiation between the two subjects. The above green preference model can be incorporated into the GSC supplydemand model and dynamic game model, and map the actions in each stage into different states. Therefore, the model is sensitive to the actions of each subject, provided that the actions of a subject are independent of and unknown to the other subject.

\section{EXPERIMENTS AND RESULT ANALYSIS}

To verify its effectiveness, the multi-agent GSC management model for retailers was applied to the GSC of green paper products, in consideration of the relevant government subsidy policies. To evaluate the greenness of the model, the domains of the 21 indices were determined in the first place. Next, an error function was established to calculate the deviation of the evaluated greenness from the actual greenness. If the deviation was zero, the error was recorded as zero; otherwise, the error was calculated by the error function. Table 1 presents the greenness evaluation results on the model. It can be seen that the calculated error of overall greenness was 0.018 , slightly lower than the standard value recognized by GSC experts. From the perspective of sustainable development, greater efforts need to be paid to the implementation of green management index $g_{5}$. 
Table 1. The greenness evaluation results on the multi-agent GSC management model for retailers

\begin{tabular}{cccc|cccc}
\hline Index & Weight & Single error & Composite error & Index & Weight & Single error & Composite error \\
\hline$g_{1}$ & 0.172 & & & $g_{2}$ & 0.143 & & \\
$g_{11}$ & 0.293 & 0.021 & 0.022 & $g_{21}$ & 0.213 & 0.009 & \\
$g_{12}$ & 0.311 & 0.019 & & $g_{22}$ & 0.260 & 0 & 0.013 \\
$g_{13}$ & 0.224 & 0.022 & & $g_{23}$ & 0.384 & 0.005 & \\
\hline$g_{3}$ & 0.241 & & & $g_{4}$ & 0.163 & & \\
$g_{31}$ & 0.151 & 0 & & $g_{41}$ & 0.301 & 0.027 & \\
$g_{32}$ & 0.199 & 0.025 & 0.011 & $g_{42}$ & 0.205 & 0.032 & 0.029 \\
$g_{33}$ & 0.201 & 0.022 & & $g_{43}$ & 0.109 & 0.025 & \\
$g_{34}$ & 0.208 & 0.019 & & $g_{44}$ & 0.222 & 0.029 & \\
\hline$g_{5}$ & 0.050 & & & $g_{6}$ & 0.231 & & \\
$g_{51}$ & 0.139 & 0 & & $g_{61}$ & 0.403 & 0.027 & \\
$g_{52}$ & 0.212 & 0.029 & 0.017 & $g_{62}$ & 0.117 & 0.032 & 0.027 \\
$g_{53}$ & 0.358 & 0.036 & & $g_{63}$ & 0.249 & 0.029 & \\
$g_{54}$ & 0.241 & 0.031 & & & & & \\
\hline
\end{tabular}

Next, the solutions of complex formulas were approximated on MATLAB to disclose the relationships between product greenness and government subsidy, and between degrees of green preferences among enterprises. Table 2 compares the parameters of the multi-agent GSC supply-demand model: the government would subsidize the supply chain enterprises, when the greenness of products reached 4.5. As can be seen from Table 1, government subsidy lowered the price and boosted the sales of type II green products, which surpass the requirements for government subsidy, thereby enhancing the profits of supply chain enterprises; government subsidy suppressed the price, sales, and profit of type I green products, which fall short of the requirements for government subsidy, resulting in a surge in total social welfare. The calculation results are consistent with the analysis results of the management model.

Figure 5 provides the curves of product greenness with the degree of green preference of retailer. From cooperation and negotiation, decentralized decision-making, and profit-sharing, the results in Figure 5 prove that the product greenness of retailer is positively correlated with the degree of green preference.

Table 2. The parameters of the supply-demand model

\begin{tabular}{cccccccc}
\hline & $\boldsymbol{p}_{\mathbf{1}}$ & $\boldsymbol{p}_{\mathbf{2}}$ & $\boldsymbol{d}_{\mathbf{1}}$ & $\boldsymbol{d}_{\mathbf{2}}$ & $\boldsymbol{\mu}_{\mathbf{1}}$ & $\boldsymbol{\mu}_{\mathbf{2}}$ & $\boldsymbol{S} \boldsymbol{W}$ \\
\hline${ }_{S}=0$ & 1.76 & 2.23 & 142 & 247 & 157.4 & 284 & 354.47 \\
$s=\hat{S}=0.5$ & 1.52 & 2.12 & 125 & 314 & 127.8 & 322 & 842.21 \\
\hline
\end{tabular}

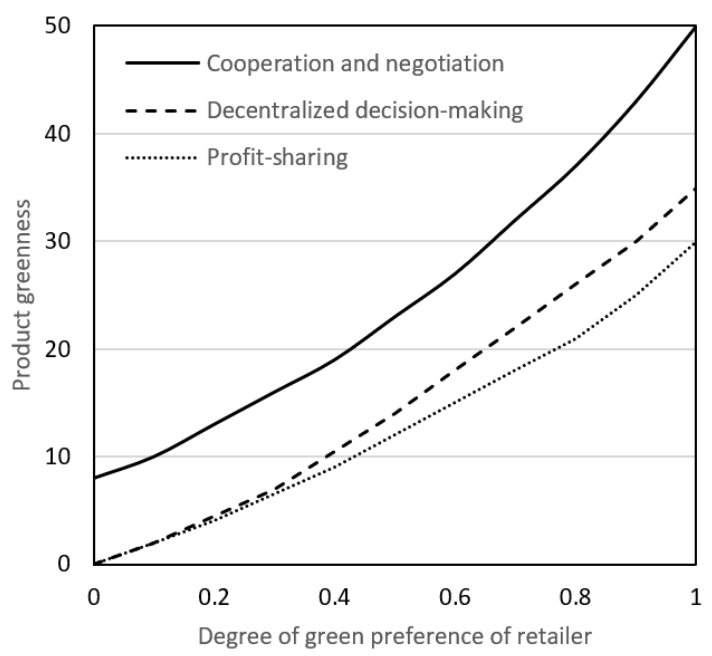

Figure 5. The variation of product greenness with the degree of green preference of retailer
Figure 6 shows the impacts of government subsidy on social welfare. It can be seen that, when social welfare was maximized, all papermakers in the market implemented multiagent GSC management, and produced green paper products. The social welfare reached RMB 754,896 yuan, when the government subsidized consumers by RMB 375.8 yuan. During the negotiation, the negotiation model can standardize the negotiation environment, and the negotiation process within and between enterprises, while resolving some conflicts in business execution and negotiation.

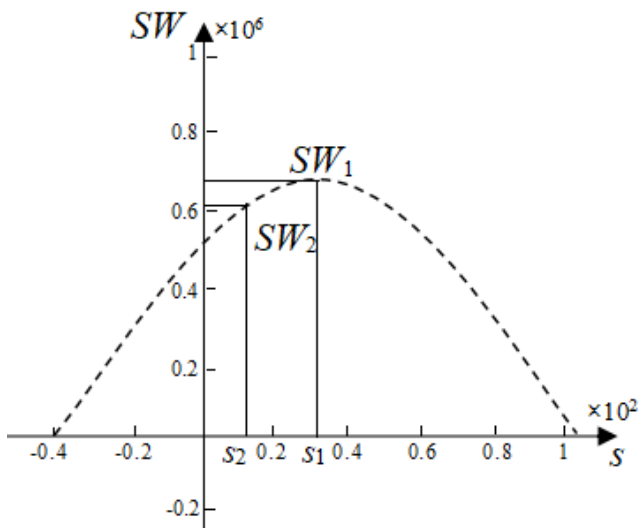

Figure 6. The impacts of government subsidy on social welfare

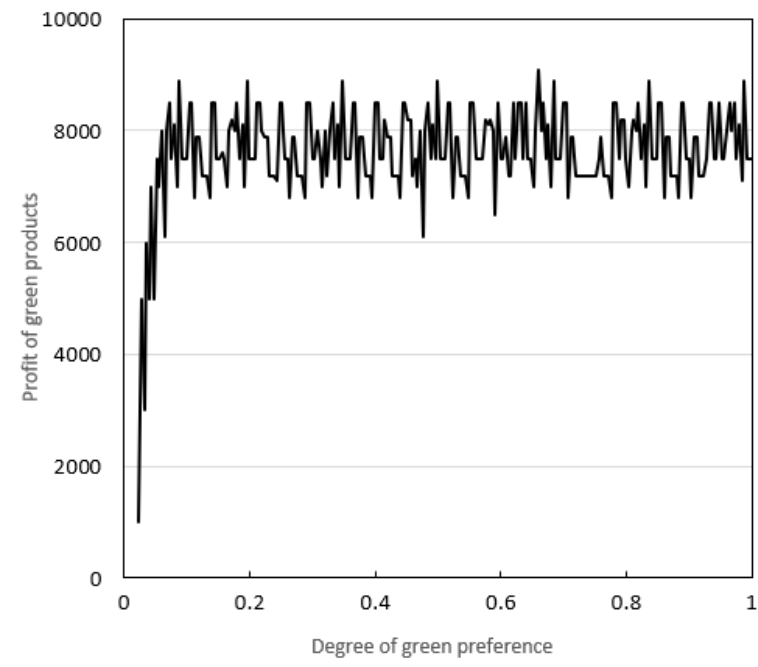

Figure 7. The variation of retailer profit with the degree of green preference 
Figure 7 shows the profit curve of retailer from green products with the degree of green preference in multi-agent GSC environment, under the coordination of the profit-sharing contract. It can be seen that, with the growing degree of green preference, the profit of retailer increased first and then tended to be stable. Hence, the retailer profit has a maximum value, when it has a certain degree of green preference. Such a retailer is willing to include factors affecting the environment into the decision-making process.

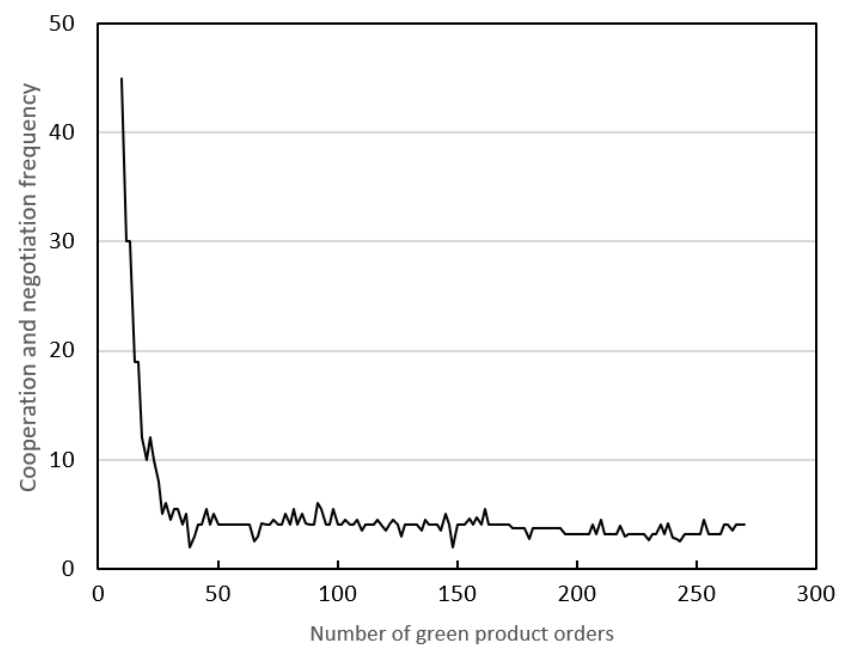

Figure 8. The variation of the cooperation and negotiation frequency with the number of green product orders

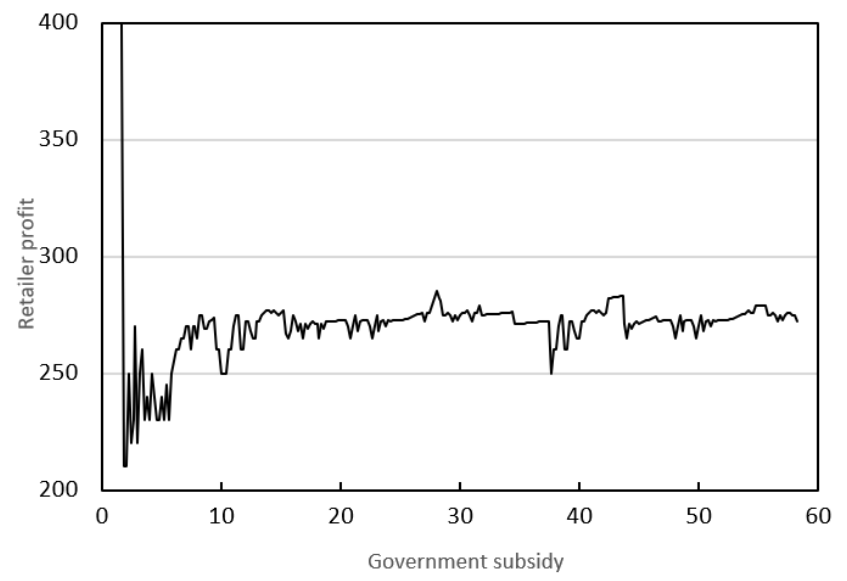

(a)Retailer

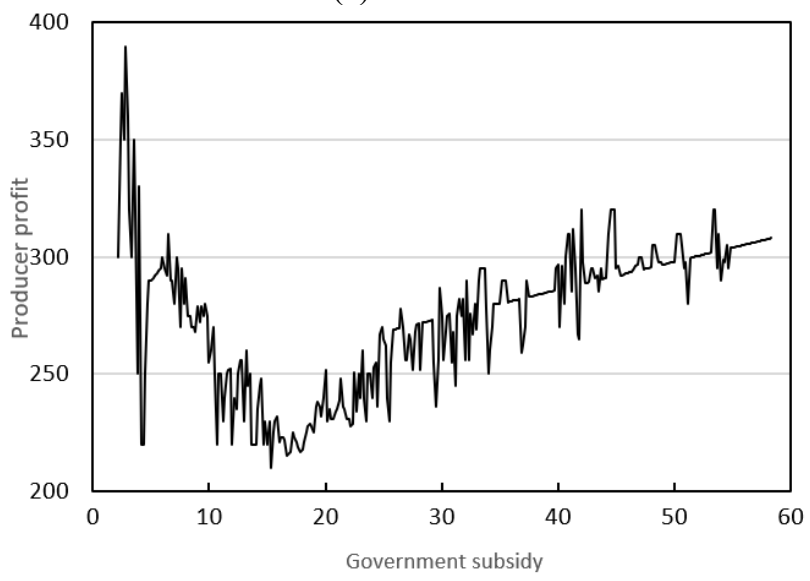

(b)Producer

Figure 9. The variations of retailer profit and producer profit with government subsidy
Figure 8 presents the variation of the cooperation and negotiation frequency with the number of green product orders in multi-agent GSC. The experimental results were relatively stable and slightly volatile under the two indices. This means the operating risks of all enterprises will decline and stabilize, after scientific cooperation and negotiation models are adopted and adjusted as per the actual situation of each enterprise.

Figure 9 records the variations of retailer profit and producer profit with government subsidy. It can be seen that, with the growing government subsidy, the profits of retailer and producer under our model both decreased first and then increased. The government subsidy motivates the producer to renovate green manufacturing technology, and the retailer to further promotes green products.

\section{CONCLUSIONS}

This paper mainly puts forward a multi-agent GSC management system for retailers. Under the framework of multi-agent GSC management system, a three-layer hierarchical EIS was created for the greenness of GSC management. From the angle of sustainable development, the experimental results show that the green management strategy of index $g_{5}$ must be further promoted. In addition, the authors modeled the supply-demand relationship and dynamic game of multi-agent GSC. Through experiments, it is learned that the retailer profit has a maximum value, when it has a certain degree of green preference. Such a retailer is willing to include factors affecting the environment into the decision-making process. Finally, a multi-agent GSC management model was constructed, followed by the discussion of the cooperation and negotiation models between the multiple agents in the system. From experimental results, it can be seen that the profits of retailer and producer under our model both decreased first and then increased, after they received government subsidy. This means the government subsidy motivates the producer to renovate green manufacturing technology, and the retailer to further promotes green products.

\section{REFERENCES}

[1] Lan, C.F. (2019). A coordination contract for green agricultural product supply chain with stochastic output. Journal Européen des Systèmes Automatisés, 52(4): 347354. https://doi.org/10.18280/jesa.520403

[2] Laari, S., Töyli, J., Solakivi, T., Ojala, L. (2016). Firm performance and customer-driven green supply chain management. Journal of Cleaner Production, 112: 19601970. https://doi.org/10.1016/j.jclepro.2015.06.150

[3] Zhao, Y.X. (2019). Optimal decision-making for green supply chain based on overconfidence under the carbon emission constraint. Journal Européen des Systèmes Automatisés, 52(2):

199-204 https://doi.org/10.18280/jesa.520213

[4] Uygun, Ö., Dede, A. (2016). Performance evaluation of green supply chain management using integrated fuzzy multi-criteria decision making techniques. Computers \& Industrial Engineering, 102: 502-511. https://doi.org/10.1016/j.cie.2016.02.020

[5] Kusi-Sarpong, S., Sarkis, J., Wang, X. (2016). Assessing green supply chain practices in the Ghanaian mining industry: A framework and evaluation. International 
Journal of Production Economics, 181: 325-341. https://doi.org/10.1016/j.ijpe.2016.04.002

[6] Ameknassi, L., Aït-Kadi, D., Rezg, N. (2016). Integration of logistics outsourcing decisions in a green supply chain design: a stochastic multi-objective multiperiod multi-product programming model. International Journal of Production Economics, 182: 165-184 https://doi.org/10.1016/j.ijpe.2016.08.031

[7] Singh, A., Trivedi, A. (2016). Sustainable green supply chain management: trends and current practices. Competitiveness Review, 26(3): 265-288. https://doi.org/10.1108/CR-05-2015-0034

[8] Taleizadeh, A.A., Alizadeh-Basban, N., Sarker, B.R. (2018). Coordinated contracts in a two-echelon green supply chain considering pricing strategy. Computers \& Industrial Engineering, 124: 249-275. https://doi.org/10.1016/j.cie.2018.07.024

[9] Yang, Z., Sun, J., Zhang, Y., Wang, Y. (2018). Peas and carrots just because they are green? Operational fit between green supply chain management and green information system. Information Systems Frontiers, 20(3): 627-645. https://doi.org/10.1007/s10796-0169698-y

[10] Ninlawan, C., Seksan, P., Tossapol, K., Plada, W. (2018). The implementation of green supply chain management practices in economics industry.

[11] Xiong, C.F. (2016). Research on the selection of real estate green supply chain partners based on BP neural network--an example of material equipment supplier. Chongqing University, Chongqing, China.

[12] Fahimnia, B., Sarkis, J., Davarzani, H. (2015). Green supply chain management: A review and bibliometric analysis. International Journal of Production Economics, 162: 101-114. https://doi.org/10.1016/j.ijpe.2015.01.003

[13] Mishra, D., Gunasekaran, A., Papadopoulos, T., Hazen, B. (2017). Green supply chain performance measures: A review and bibliometric analysis. Sustainable Production and Consumption, 10: 85-99. https://doi.org/10.1016/j.spc.2017.01.003

[14] Sarkis, J., Dou, Y. (2017). Green supply chain management: A concise introduction. Routledge.
[15] Zhou, Y., Gong, D.C., Huang, B., Peters, B.A. (2015). The impacts of carbon tariff on green supply chain design. IEEE Transactions on Automation Science and Engineering, 14(3): 1542-1555. https://doi.org/10.1109/TASE.2015.2445316

[16] Coskun, S., Ozgur, L., Polat, O., Gungor, A. (2016). A model proposal for green supply chain network design based on consumer segmentation. Journal of Cleaner Production, 110: 149-157. https://doi.org/10.1016/j.jclepro.2015.02.063

[17] Yu, H., Solvang, W.D., Solvang, B. (2016). A Goal Programming Approach for Green Supply Chain Network Optimization. https://doi.org/10.2991/iwama16.2016.17

[18] Wang, Z., Mathiyazhagan, K., Xu, L., Diabat, A. (2016). A decision making trial and evaluation laboratory approach to analyze the barriers to green supply chain management adoption in a food packaging company. Journal of Cleaner Production, 117: 19-28. https://doi.org/10.1016/j.jclepro.2015.09.142

[19] Khan, S.A.R. (2018). Introductory chapter: introduction of green supply chain management. In Green Practices and Strategies in Supply Chain Management. IntechOpen. https://doi.org/10.5772/intechopen.81088

[20] Agi, M.A., Nishant, R. (2017). Understanding influential factors on implementing green supply chain management practices: An interpretive structural modelling analysis. Journal of Environmental Management, 188: 351-363. https://doi.org/10.1016/j.jenvman.2016.11.081

[21] Alananzeh, O., Algiatheen, N., Ryati, R., Albayyari, R., Tarhini, A. (2017). The impact of employee's perception of implementing green supply chain management on hotel's economic and operational performance. Journal of Hospitality and Tourism Technology. https://doi.org/10.1108/JHTT-02-2017-0011

[22] Younis, H., Sundarakani, B. (2019). The impact of firm size, firm age and environmental management certification on the relationship between green supply chain practices and corporate performance. Benchmarking: An International Journal, 27(1): 319-346. https://doi.org/10.1108/BIJ-11-2018-0363 